out to study Science-and-all-that: but no; he had the true scientific humility to study that with which he was most familiar.

If I have made this review rather an obituary notice than a deeper examination of Errington's research it is because Paul was a dear friend and lovable man whose philosophy was native and truthful. His contributions to science we can take for granted; he sought truth with a burning intensity. One last word : Errington held a research chair at Iowa State University for thirty years, relieved of formal lecturing and departmental management; we owe thanks to that institution for such enlightenment.

FRANK DARLING

Desert Animals. By K. Schmidt-Nielsen. Oxford University Press, 45s.

Man may be versatile, but he is no match for a hot, dry desert. Many animals, however, have become specialised for life in this hostile environment. Dr. Schmidt-Nielsen examines them in turn and analyses the various ways in which they have managed to solve this difficult problem. The more important and interesting desert species, such as the camel, donkey, sheep, rabbit, ground squirrel, pack rat and kangaroo rat, are each allocated a whole chapter. In addition there are chapters dealing with cattle, carnivores, rodents, marsupials, birds and reptiles. Members of the Fauna Preservation Society will be surprised to learn that the Arabian oryx receives no mention, probably because so little is known about it.

What are the basic solutions to existence under the desert sky? One is to be very small and to burrow underground during the heat of the day. Another is to be very large, so that cooling can be achieved by the loss of large amounts of water by evaporation. This water loss can be stepped up by sweating and panting, but there are obviously limits to the quantities of liquid that can be used up in an environment where there is no easily available drinking water. Of the bigger species, the camel is the best at coping with high temperatures. Contrary to popular opinion it does not store water, either in the hump or in the stomach, but relies on its ability to withstand remarkable degrees of dehydration and fluctuating body temperatures. It also has a carefully controlled system of water losses. There is evidence to show that a camel can tolerate a dehydration loss of over a quarter of its total body weight; half this loss would kill any other mammal.

Beautifully written, well produced and expertly presented, this will no doubt remain the standard work on the subject for many years to come. The summaries at the end of each chapter are extremely helpful; if only more books of this sort would follow this practice, how much easier it would be to check basic facts quickly.

DESMOND MORRIS

\title{
Animal Worlds. By Marston Bates. Nelson, 84s.
}

The high price, large quarto format and dazzling collection of photographs (nearly 250, of which 100 are in colour) suggest that this may be another ' glossy' production with a perfunctory text. Nothing could be further from the truth. The photographs are, admittedly, superbly reproduced, and illustrating animals and habitats from all parts of the world, so that many ' readers' will find the book worth the price for these alone. But Professor Bates has provided also a detailed and well-judged text in which the pleasure and enthusiasm of the naturalist are blended with the biologist's eye for discerning the patterns and processes in habitats and animal communities. The author, after a brief introductory background about ecological principles in which technical terms are kept to the minimum, proceeds to a survey of 
the main major habitats of the world-the sea and its various sub-divisions, the fresh waters, grasslands, desert, forest and so on. In each section he considers the physical characteristics which limit the animal and plant community which has developed and, at the same time, the way in which the latter has evolved to exploit the potentialities of the environment to the full. In his survey he comments on the effects of man on these communities, and in his final chapters points out the cumulative impact of man's activity upon the world as a whole. The horrifying nature of the degradation and imbalance produced is all the more impressively conveyed through being unfolded, step by step, in this way, and in such restrained and objective language.

This particular combination of outstanding photographs, well chosen and reproduced, with an informed and thoughtful textual survey, can put a complete and vivid record of the world's habitats and animals into our hands. We cannot now say we do not know what we are losing.

\section{H. N. SOUTHERN}

\section{Charles Darwin. Evolution by Natural Selection. By Sir Gavin de} Beer. British Men of Science Series. Vol. 1. Nelson, 21s.

\section{Biologist and Philosopher. A Study of the Life and Writings of} Alfred Russel Wallace. By Wilma George. Abelard-Schuman, 25s.

The names of Darwin and Wallace will always be associated in histories of the revolution in scientific thought begotten of these two men in midnineteenth century, yet Darwin's fame has far surpassed Wallace's. The story of the Linnean Society's meeting in 1858 has often been told, when their two separate statements of the idea of natural selection were jointly read and subsequently published, to be followed by an enduring friendship and mutually generous acknowledgment of the other's work. Of actual priority there was never any question: Darwin's Linnean contribution dated back fourteen years ; Wallace's share came direct from Ternate in the Moluccas, where during an attack of fever in 1858, the idea of natural selection had dawned on him-" Then it suddenly flashed upon me that this self-acting process would necessarily improve the race, because in every generation the inferior would inevitably be killed off and the superior would remain-that is, the fittest would survive." Wallace followed Herbert Spencer in this tautology.

Has posterity adjudicated fairly in the last hundred years? These two volumes give readers an admirable opportunity to judge for themselves. Sir Gavin de Beer's book is intended for the wide public who need up-todate information on the great minds that have changed current beliefs. His researches into Darwin's previously unpublished early note-books, give him, with his many other qualifications, a pre-eminent authority in tracing the genesis and growth of Darwin's ideas ; he describes with a deep understanding the searching, self-critical, theory-building quality of Darwin's thought. So that when Wallace's letter to Darwin in 1858 fired Darwin to immediate publication, halting him in his longer work already in hand, and compelling him to focus his whole attention on convincing the world in as short a volume as he could compass, that evolution was a universal force through the mediation of natural selection, we can understand how the condensed arguments and frankly faced difficulties compelled immediate attention. Wallace as midwife to the birth of "The Origin" has a unique place in the literary history of evolution quite apart from his own achievements.

Wilma George, lecturer and tutor in zoology, writer on genetics and 